1. Um mercado diferente; 2. Uma visita de três minutos; 3. O Departamento de Marketing ideal; 4. O lançamento de um produto novo; 5. Comentários finais.

Luiz Fernando Kiehi *

* Gerente de produtos dos Laboratorios Lepetite S.A. e editor da revista Rassegna Medica e Cultural.

\section{Um mercado diferente}

Situado num meio-termo entre o mercado de produtos de consumo $e$ de produtos industriais, 0 mercado farmacêutico apresenta caracteristicas de ambos, simultaneamente.

Vejamos quais são essas caracteristicas especiais:

a) é um dos únicos mercados em que o consumidor final não decide a compra, embora seja ele quem execute o ato de comprar. De fato, na maioría dos casos, é o médico quem decide a compra ao receitar o medicamento no final da consulta. Portanto, é a ele e não ao consumidor, que é necessário convencer sobre a qualidade do produto;

b) a decisão de compra (receita) é tomada em hora e local diferentes do ato de compra. Essa decisão de compra, feita pelo doutor, pode ser alterada no ato da compra como, por exemplo, pela influência do balconista da farmácia, que pode oferecer ao consumidor "a mesma coisa, muito melhor e bem mais em conta";

c) a escolha por parte do médico de um medicamento e não de outro igualmente correto, é feita com base estritamente racional, embora na prática nem sempre seja isso o que ocorre;

d) embora existam cerca de 40 mil médicos em atividade no País é extremamente raro encontrarmos em determinada hora e local um agrupamento de médicos em situação de disponibilidade para a recepção da mensagem do fabricante. Por outro lado, o uso dos meios de comunicação de massa para a divulgação de produtos farmacêuticos, destinados ao grande público, é proibido por lei, salvo no caso de raras exceçôes como certos tipos de analgésicos, antiácidos ou vitaminas. Dal decorre a mais paradoxal caracteristica do marketing da indústria farmacêutica: na era da comunicação de massa, a propaganda de produtos farmacêuticos tem de ser feita nos moldes medievais do contato homem a homem. E a mal compreendida visita médica, na qual o propagandista do laboratório procura o médico no seu consultório, no ambulatório ou nos corredores do hospital e dá seu recado da melhor maneira possivel.

A visita médica é indispensável por ser praticamente o único meio de que dispóe o médico, principalmente o do interior, para se manter atualizado quanto aos progressos da farmacoterapêtica. Entretanto, o custo da visita médica é muito alto, se

$13(3): 141-150$

jul./set. 1973 
levarmos em conta os salários dos propagandistas com os respectivos encargos sociais, e o custo das amostras de medicamentos e folhetos promocionais entregues gratuitamente em cada visita médica. Esse alto custo da visita médica, aliado ao custo de distribuição dos produtos, faz com que as despesas de marketing participem com uma percentagem elevada na composição do preço final do produto $(20$ a $30 \%$ dependendo do volume de vendas do laboratório), dando uma falsa idéia de desperdício de recursos.

A visita médica, às vezes apenas tolerada por parte dos médicos, se não é interessante para a população, porque encarece o preço final dos medicamentos, também não o é para os laboratórios. Se sua eliminação fosse viável, isso permitiria a adoção de uma estrutura de marketing muito mais flexível e econômica, e a proporcional redução do preço final dos produtos seria compensada pela possibilidade de se vender maiores quantidades, atingindo todo um segmento da população atualmente marginalizado do mercado farmacêutico por não ter poder aquisitivo.

Eliminados os veículos de comunicação de massa, restam os recursos da mala direta (envio de material promocional pelo correio) e anúncios veiculados em revistas especializadas de circulação dirigida ao médico. Ambos são bastante utilizados pelos laboratórios, mas revelaram-se incapazes de substituir a visita médica. Sendo o produto farmacêutico um assunto eminentemente técnico, cuja argumentação de vendas deve ser de ordem racional, esses dois recursos têm-se revelado incapazes de substituir o diálogo com um profissional especializado, como o propagandista de laboratório, durante o qual ocorre a oportunidade de perguntas $\mathrm{e}$ respostas informais e esclarecimentos oportunos sobre eventuais dúvidas que o médico possa ter.

142 A mala direta e 0 anúncio em revista especializada têm sua utilidade como lembrete, reforçando um comportamento já adotado pelo doutor, mas dificilmente um médico responsável começará a prescrever um produto baseando-se apenas na comunicação recebida através daquele dois veículos promocionais;

e) o produto farmacêutico chega ao consumidor final através da farmácia ou de instituições como hospitais e ambulatórios, governamentais ou particulares.

A venda à farmácia pode ser feita diretamente ou por intermédio de atacadista e distribuidores.
A economia resultante dessa segunda alternativa é muito pequena porque os propagandistas dos laboratórios farmacêuticos também acumulam as funções de vendedores, já que no seu itinerário da visitação médica eles forçosamente passam perto das farmácias. Não se deve esquecer que os laboratórios visitam mensalmente de 30 a $35 \mathrm{mil}$ médicos em todo o País e vendem a apenas cerca de oito mil farmácias, com uma média de oito pedidos por ano por farmácia.

$A$ venda às instituições governamentais é sempre feita por meio de concorrências públicas, não envolvendo grande custo de marketing (isso aliado à compra de grandes quantidades, é o que permite aos laboratórios reduzirem seus preços para a venda às instituições). Mesmo a venda às instituições particulares, quando não ocorre através de concorrências, não exige muito tempo do propagandista vendedor.

Assim, a utilização de atacadistas ou distribuidores jamais contribuirá significativamente para a redução dos custos de comercialização dos medicamentos;

f) recursos como descontos em valor ou bonificações em mercadorias são mera ilusão no mercado farmacêutico, uma vez que o balconista tem poucas oportunidades para passar ao consumidor a maior quantidade comprada em função dessas facilidades. Segundo várias pesquisas realizadas, 0 balconista tem oportunidade de exercer influência em apenas cerca de $5 \%$ dos atos de compra. Tanto isso é fato que, quando ainda não haviam as portarias governamentais estabelecendo limites máximos para descontos e bonificações a serem oferecidos pela indústria farmacêutica, muitos laboratórios fizeram a amarga constatação de que utilizando-se desses recursos estavam apenas provocando, a médio prazo, uma superestocagem no nível das farmácias. Em outras palavras, estavam vendendo mais barato apenas o que iriam vender daqui a alguns meses pelo preço de tabela. No mercado farmacêutico há poucas alternativas. A única venda saudável é a que tem origem direta ou indireta no receituário médico.

\section{Uma visita de três minutos}

No Brasil quase não há possibilidade de seleção dos médicos a serem visitados pelos propagandistas. Embora com fortes concentrações regionais que provocam um desequilíbrio em favor das grandes cidades, 0 índice brasileiro de um médico para

Revista de Administração de Empresas 
2500 habitantes, quando a Organização Mundial da Saúde considera ideal a média de um médico para cada mil habitantes, indica que quase todos os médicos brasileiros possuem pelo menos uma clientela razoável.

É comum um médico possuir poucos clientes no consultório particular, mas atender a 25 pacientes em quatro horas de trabalho no ambulatório do INPS, por exemplo.

Muitas vezes um médico de bairro, com clientela de baixo poder aquisitivo, atende a mais pacientes do que um médico famoso com consultório luxuoso freqüentado por uma elite.

Mesmo um professor de faculdade, que dedica pouco tempo à clínica prática, é importante para - laboratório pela influência que exerce junto a seus alunos e assistentes.

Como cada propagandista faz uma média de 10 visitas diárias (além das visitas de venda às farmácias e instituições), cada um possui uma área de 200 médicos. É necessário, portanto, uma equipe de cerca de 150 propagandistas para que o laboratório tenha uma razoável cobertura nacional.

Um médico recebe, em média, cinco propagandistas por dia e, salvo casos excepcionais de apresentação de produto novo, não permite que cada um fale mais de três minutos, em vista da exigüidade e preciosidade de seu tempo. Esses três minutos permitem a argumentação em torno de um máximo de três produtos, além da entrega de amostras de dois ou três outros produtos já sobejamente conhecidos.

A necessidade de aproveitar da melhor forma possivel esses caríssimos três minutos mensais, com cada médico, levou os laboratórios a aperfeiçoarem ao máximo a técnica de transmitir uma mensagem racional capaz de despertar a atenção do visitado, no sentido de diferenciar um produto do concorrente e capaz de fixar essa mensagem pelo menos por algum tempo.

Inicialmente, é necessário despertar a atenção do médico para o discurso que se seguirá, através de um problema terapêutico concreto para o qual não se achou ainda uma solução. Por exemplo, em certas indicações, os medicamentos existentes produzem efeitos colaterais, dos quais os pacientes costumam queixar-se para 0 médico; 0 propagandista apresenta, então, um produto com os mesmos valores terapêuticos dos de seus concorrentes, mas com a vantagem de não produzir os efeitos colaterais, graças a uma nova fórmula de composição.
Despertada a atenção do médico, é preciso informá-lo racionalmente sobre as razões pelas quais o produto é mais eficaz que os concorrentes ou porque não apresenta algumas de suas desvantagens.

Finalmente, a partir do momento em que o médico se convence das razões pelas quais em tais indicações ele deve receitar "nosso" produto e não de outro, é preciso insistir sobre as diversas formas de apresentação e a posologia recomendada para cada caso, para que ele não se engane ao prescrevê-lo.

Em vista desses fatos, torna-se evidente a grande importância do uso dos folhetos promocionais por parte do propagandista. Por meio desses recursos, a visita médica torna-se uma verdadeira apresentação audiovisual dos produtos oferecidos, em que a exposição oral do propagandista e as imagens e palavras dos folhetos devem-se completar na consecução do alvo.

Simultaneamente, o folheto, além de funcionar como um roteiro do speech do propagandista, no qual ele se apóia em caso de dúvida, tem ainda a virtude de permitir certa padronização da mensagem da visita médica.

$\mathrm{Na}$ medida em que os laboratórios vão sendo obrigados a aprimorar cada vez mais as técnicas de propaganda através da visita médica, pressionados que são pela concorrência acirrada e pelo alto custo por visita, há a tendência de os médicos tornarem-se cada vez mais exigentes quanto ao conteúdo das mensagens, e menos dispostos a perder seu precioso tempo com trivialidades. Assim, certamente ocorrerá no Brasil o que já ocorreu nos países europeus e nos Estados Unidos: uma elevação de nível cultural do propagandista e uma redução no número de visitas anuais a cada médico porém, com maior duração para cada uma. Em alguns países europeus mais desenvolvidos, todos os propagandistas têm nível universitário (medicina ou farmácia) e os médicos recebem cada propagandista apenas quatro a seis vezes por ano, em visitas de 10 a 20 minutos cada.

Entretanto, ainda serão necessários alguns anos para que a indústria farmacêutica brasileira atinja esse estágio.

Não devemos esquecer que, embora cerca de metade dos médicos, principalmente os de pequenas cidades, sejam clínicos gerais, a outra metade distribui-se entre as diversas especialidades médicas (ginecologia, cardiologia, psiquiatria, pediatria, etc.). Em consequiência disso, e também por- 
que o tempo disponível da visita só permite a abordagem de poucos produtos, a mensagem de cada produto deve ser adequada às necessidades de cada especialista visitado. Pelas mesmas razões, nem sempre os produtos apresentados ao clínico geral serão os mesmos a serem abordados junto ao cardiologista. (Nos anexos 1 e 2 apresentamos um modelo de plano promocional para um trimestre).

\section{O departamento de marketing ideal}

Com todas essas dificuldades que envolvem a propaganda de produtos farmacêuticos, observa-se que além de contar com competente gerente de vendas (chefe dos gerentes das filiais regionais), o gerente de marketing de um laboratório precisa apoiar-se em três assessorias fundamentais: a gerência de propaganda, a gerência médica e a gerência de pesquisas de mercado.

\subsection{O DEPARTAMENTO MÉDICO}

Todo laboratório farmacêutico possui um departamento composto por um ou mais médicos, chamado gerência médica, departamento científico, ou algo semelhante.

Três são as principais funções da gerência médica:

a) entrar em contato com importantes médicos e conseguir que eles se disponham a conduzir testes clínicos com os produtos do laboratório nos hospitais em que trabalham, auxiliando-os na elaboração dos testes, fornecendo os medicamentos necessários e acompanhando a realização das experiências;

b) a outra função é a de assessorar o departamento de marketing na elaboração e redação de manuais de treinamento de propagandistas vendedores;

c) finalmente, a terceira grande função da gerência médica é a de assessorar o departamento de marketing na elaboração e redação do material promocional do laboratório, evitando que os foIhetos sejam publicados com erros de conceito ou vocabulário inconveniente, explicando a melhor forma de transmitir a seus colegas médicos cada característica do produto.

\subsection{O DEPARTAMENTO DE PROPAGANDA}

A gerência de propaganda tem duas funções fundamentais. Uma delas é a coordenação, junta- mente com o departamento médico, do patrocínio de congressos médicos sobre temas relacionados com os produtos do laboratório.

A outra função, que toma maior parte do seu tempo, é a criação, redação e produção do material promocional a ser utilizado pela equipe de propagandistas e providenciar para que esse material promocional, juntamente com as amostras, chegue, a todas as filiais antes da reunião mensal em que os gerentes treinam suas equipes sobre 0 plano promocional que se desenvolverá nos próximos 30 dias.

A elaboração desse material promocional exige grande esforço de criação, pois nem sempre é fácil encontrar um tema de interesse para o médico sobre um produto já bastante conhecido.

O bom gerente de propaganda é, portanto, um homem raro, uma vez que dele se exige, simultaneamente, grande criatividade, boa base científica que the permita compreender a fundo os produtos do laboratório e suas características, e bastante conhecimento de visitação médica.

A começar pela própria terminologia utilizada, a propaganda de produtos farmacêuticos tem características tão especiais que dificilmente uma agência de propaganda pode desempenhar com sucesso a parte de criação.

Por esta razão a criação das campanhas promo. cionais costuma ser feita pelos departamentos de propaganda dos laboratórios, assim como a coordenação da produção desse material promocional. Por outro lado, a produção dos folhetos, anúncios, etc. (isto é, fotos, composição, arte final, fotolitos, impressão, etc.) costuma ser feita mais economicamente através de free-lancers e empresas especializadas.

\subsection{GERENCIA DE PRODUTOS}

Se numa empresa de produtos de consumo já é difícil coordenar as atividades dos gerentes de produtos com as atividades dos diversos departamentos "executivos", num laboratório de produtos farmacêuticos a dificuldade é ainda maior.

$\mathrm{Na}$ empresa de produtos de consumo, grande parte da verba de propaganda de cada produto é destinada à produção e veiculação de propaganda em meios de comunicação em massa (rádio, TV, revistas, etc.). Sendo assim, o gerente de produtos possui uma grande autonomia sobre a verba de propaganda atribuída a seus produtos. 
No caso do laboratório farmacêutico, o gerente de produtos não tem essa autonomia porque mais de $80 \%$ da verba de propaganda de todos os produtos concentram-se no propagandista e no material utilizado por ele $e$, portanto, a freqüência $e$ os recursos da propaganda de cada produto depende dos demais produtos.

Apesar dessa dificuldade, os gerentes de grupos de produtos são extremamente úteis para um laboratório. Basta observar que nem o gerente de marketing, nem os três pilares em que ele deve apoiar-se (depto. médico, depto. de propaganda e depto. de pesquista de mercado) têm tempo suficiente para se dedicarem a cada um dos muitos produtos da linha do laboratório. Disso resulta que muitas oportunidades de mercado passam despercebidas e as soluções de sérios problemas especlficos são adiadas indefinidamente, sendo que alguns nem sequer são notados.

Por estas razões achamos que, sempre que as finanças o permitissem, o laboratório farmacêutico deveria eliminar a gerência de propaganda e substituí-la por três ou quatro gerentes de grupo de produtos, os quais, entre outras atividades, exerceriam as funções de gerente de propaganda de seu grupo de produtos.

A dificuldade mencionada no início desse tópico pode ser facilmente contornada desde que o gerente de marketing, no início do ano, atribua a cada gerente de grupo de produtos uma verba de propaganda e um conjunto de "espaços" (posições) no plano anual de visita médica. Cada gerente de grupo de produtos administrará essa verba e esses "espaços" da forma que julgar mais inteligente, distribuindo-os entre os produtos de seu grupo. Naturalmente, os planos de cada um devem ser aprovados pelo gerente de marketing, que é o único que possui uma visão global do complexo mercadológico da empresa.

\subsection{DEPARTAMENTO DE PESQUISAS DE MERCADO}

O terceiro sustentáculo da gerência de marketing de uma laboratório é o departamento de pesquisas de mercado. Suas funções básicas são a obtenção do maior número possivel de dados sobre o mercado e a realização de análises especiais.

Se bem aproveitado, o gerente de pesquisas de mercado pode ter funções bem mais amplas do que as de seu colega de uma indústria de produtos de consumo, tornando-se o principal assessor do gerente de marketing.

Em geral, por sua visão ampla da situação da empresa no mercado farmacêutico é êle o mais indicado para elaborar as previsões de vendas em unidades e valores, tanto a curto prazo, para orientação do planejamento da produção, como a médio e longo prazo, para o estabelecimento de objetivos de vendas e de estratégias promocionais.

Talvez seja a indústria farmacêutica o ramo que mais dispõe de informações sistemáticas sobre o mercado.

No mundo inteiro, e principalmente no Brasil, o sistema de troca de informações fidedignas sobre - volume de vendas, número de propagandistas, salários, prêmios e diárias e participação no mercado e outras, funciona entre os laboratórios de modo rotineiro.

Empresas internacionais de pesquisas de mercado especializadas abastecem os laboratórios farmacêuticos com painéis periódicos contendo uma infinidade de informações detalhadas sobre vendas e receituário médico por produto e por diagnóstico.

A partir desses dados o gerente de pesquisas de mercado está em condições de realizar uma série de estudos de ordem geral, sempre comparando os índices de marketing de sua empresa com a média dos indices das empresas concorrentes.

Finalmente, a grande função do gerente de pesquisas de mercado é a elaboração e condução de enquetes por meio de entrevistas junto a médicos, coletando informações ou opiniōes sobre assuntos especificos, quando estas não são disponíveis nos painéis mencionados.

\section{O lançamento de um produto novo}

Apresentaremos a seguir um exemplo de estratégia de marketing utilizada por um laboratório para - lançamento de um novo produto. 0 caso que serve de exemplo foi escolhido por ser menos complexo do que a maioria dos lançamentos da indústria farmacêutica e, ao mesmo tempo, completo na sua simplicidade.

Trata-se do caso real do lançamento de um analgésico ético (propaganda dirigida exclusivamente a médicos), cujo planejamento descreveremos com algumas simplificações destinadas a facilitar ao leitor uma visão de conjunto do processo. 


\subsection{PRELIMINARES}

Dentre os produtos que um laboratório poderia lançar em futuro próximo, constava um analgésico específico para dores de cabeça. Sua fórmula continha quatro componentes: uma ergotamina, uma dose de cafeína, um componente analgésico geral e um calmante em pequena dosagem.

$\mathrm{Na}$ bula elaborada pelo departamento médico constavam as seguintes indicações:

Cefaléia por tensão nervosa ou muscular; Cefaléia devida à hipertensão arterial; Cefaléia vasomotora devida às alterações do tempo;

Cefaléia conseqüente de afecções dos olhos, nariz, ouvidos e dentes;

Cefaléia provocada por infecções em geral;

Enxaqueca.

O gerente de marketing da empresa solicitou ao gerente de pesquisa de mercado que analisasse as possibilidades que 0 produto poderia ter no mercado nacional.

\subsection{PESQUISA DE MERCADO ENTRA EM AÇĀO}

Consultado pelo gerente de pesquisa de mercado, o chefe do departamento médico informou-o sobre a função de cada componente da fórmula e as razões de sua presença. Informou ainda que, embora aquele produto não pudesse ser considerado como novidade, tratava-se de uma "feliz combinação" de elementos que certamente teria eficientes resultados quando empregada na prática. Em outras palavras era o "bom senso em analgésico para cefaléia".

No painel de vendas o gerente de pesquisas de mercado confirmou que o grupo dos analgésicos é um dos que apresentam maior volume de ven146 das do mercado farmacêutico, tendo crescido firmemente nos últimos anos, sempre com índices de dinamismo superiores ao do mercado total. Essse grupo, mesmo excluindo-se os analgésicos populares (aqueles com propaganda junto ao grande público e com vendas até em bares), é composto por vários produtos em acirrada competição.

No painel de receituário, encontrou um volume de receitas de analgésicos compatível com o volume de vendas e observou que esse tipo de produto é prescrito tendo em vista uma infinidade de diagnósticos. No setor "diagnósticos", do mesmo painel, verificou que o número de diagnósticos "dor de cabeça" era muito pequeno. Lembrou-se, porém, que não são freqüentes os casos em que a dor de cabeça é a única queixa do paciente. Raramente alguém vai ao médico apenas porque tem dor de cabeça, mas ao fazer uma consulta o paciente costuma mencionar a cefaléia como um dos sintomas ou como um problema secundário que $o$ aflige de tempos em tempos.

0 gerente de pesquisas de mercado considerou que o painel de receituário revelara-se insuficiente para resolver suas dúvidas e achou que o volume de vendas do grupo de analgésicos éticos (não populares) justificava uma investigação mais profunda junto aos médicos.

o painel de receituário revelava que as especialidades médicas que mais receitam analgésicos são os clínicos gerais, os pediatras, os ginecologistas, os neuropsiquiatras e os ortopedistas. Os pediatras foram eliminados dessa pesquisa porque a única apresentação do analgésico em questão era em comprimidos, incômoda para crianças, o que tornaria improvável seu receituário para menores de sete anos e também porque as dores de cabeça infantis são pouco freqüentes.

Assim, resolveu fazer uma pesquisa de 200 entrevistas igualmente distribuídas entre clínicos gerais, neuropsiquiatras, ginecologistas e ortopedistas. Para isso elaborou um questionário que tinha os seguintes objetivos:

a) verificar o mercado potencial do analgésico em questão;

b) verificar a provável aceitação do produto $\mathrm{e}$ razões;

c) procurar saber quais eram, realmente, os produtos concorrentes;

d) orientar a propaganda do lançamento (se este ocorresse).

A tabulação da pesquisa revelou os seguintes resultados:

1. Percentagens de pacientes que se queixam de cefaléias:

\section{Respostas} mais

\section{Média frequientes}

Clínicos gerais $44 \%$ dos pac. $60 \%$ dos pac. Ginecologistas $34 \%$ dos pac. $10 \%$ dos pac. Ortopedistas $\quad 28 \%$ dos pac. $5 \%$ dos pac. Neuropsiquiatras $55 \%$ dos pac. $80 \%$ dos pac.

Embora a tendência dos médicos seja a de fazer superestimativas, esses dados superaram a expectativa mais otimista. 
2. Causas mais freqüentes de cefaléias:

Respostas múltiplas menção

Tensão

Enxaqueca

Hipertensão

Olhos, etc.

Infecções

Mudanças de tempo $12 \%$ "

Os diversos especialistas responderam aproximadamente nas mesmas proporções. Entretanto, $50 \%$ dos ortopedistas mencionaram as cefaléias "por compressão da coluna vertebral".

3. Atitude ante a fórmula do produto:

Certamente receitaria

Provavelmente receitaria

Não sei

Provavelmente e certamente

não receitaria (somados)

$55 \%$

$8 \%$

$7 \%$

Nas quatro especialidades médicas entrevistadas, a soma das respostas "certamente" e "provavelmente receitaria o produto" variou entre $79 \%$ e $92 \%$.

Note-se que a experiência com esse tipo de pergunta demonstra que um índice de $35 \%$ de "certamente usaria" pode ser considerado excelente para qualquer tipo de produto, farmacêutico ou não.

0 gerente de pesquisas de mercado estimou que pelo menos $60 \%$ dos médicos entrevistados experimentariam receitar 0 analgésico estudado (35\% "certamente" mais metade dos $50 \%$ dos "provavelmente receitaria").

4. O mais surpreendente, porém, é que as respostas dos médicos revelaram uma real compreensão das virtudes da fórmula apresentada, analisando cada componente e comentando sua ação específica, com destaque para a presença da ergotamina ("ótima para cefaléias de origens vasculares" ou "a ergotamina resolve quase todos os tipos de cefaléias").

A expressão "cefaléia vascular" foi muito mencionada pelos entrevistados.

Alguns médicos demonstraram certa preocupação com a presença do calmante que, dependendo da dose, poderia provocar sonolência. $\mathrm{Na}$ conclusão de seu relatório, o gerente de pesquisas de mercado recomendou que o pro- duto fosse lançado, pois certamente seria bem aceito pelos médicos daquelas especialidades. Destacou que o eixo promocional do lançamento deveria ser a própria fórmula do produto, facilmente compreendida e aceita, com destaque para o componente derivado da ergotamina.

\subsection{NASCE UMA CAMPANHA}

De imediato evidenciou-se que, diante do potencial de mercado, o produto deveria ser lançado o mais breve possível.

A pesquisa indicara claramente que a maior parcela do mercado de dores de cabeça concentrase naquelas de origem tensional, seguida pelas enxaquecas. Estas são um tipo de afecção com sintomas e sinais específicos, embora também de origem vascular cerebral. Foi resolvido que essa indicação não seria mencionada na campanha do produto, porque a pesquisa evidenciava que os próprios médicos deduziam expontaneamente que o analgésico testado era muito bom para enxaqueca, graças à presença da ergotamina em sua fórmula.

Entretanto, o gerente de propaganda observou que as palavras "tensão" e "tensional" já estavam um pouco desgastadas pela freqüência e varieda. de de sentidos com que vinham sendo empregadas na propaganda dos mais diversos produtos farmacêuticos de quase todos os laboratórios.

Nessa altura, o gerente do departamento médico lembrou que a maioria das dores de cabeça resultam de uma tensão psíquico-emocional porque esta provoca uma insuficiência do "tônus" das artérias do cérebro. Lembrou, ainda, a existência de um trabalho clínico de um respeitável autor que afirmava que $90 \%$ das dores de cabeça são de origem vascular.

Ficou decidido, então, que o analgésico em questão teria sua propaganda centralizada numa única indicação: cefaléias de origem vascular. Com isso, indiretamente, estariam sendo englobadas quatro das seis indicações do produto: cefaléias tensionais, enxaqueca, cefaléias causadas pela hipertensão vascular e as causadas por alterações meteorológicas.

Quanto à marca do produto, que chamaremos, simbolicamente de "Cefalton", foi considerada satisfatória pelos participantes da reunião, pois lembrava "cefaléia", "analgésico" e "tônus", facilitando a memorização por parte do médico. 
Já era evidente pela pesquisa, que o produto deveria ser lançado pelo menos junto aos clínicos gerais e neuropsiquiatras. 0 gerente de marketing, considerando o bom potencial dos ginecologistas e o seu volume como categoria (quatro mil ginecologistas contra mil neuropsiquiatras no País), resolveu que o lançamento do analgésico também deveria atingir esse grupo de especialistas.

Considerando o pequeno número de ortopedistas (cerca de 700) e que a maior parte das poucas dores de cabeça de que se queixam os clientes dos ortopedistas está relacionada com problemas de coluna vertebral (fora, portanto, do espectro de ação do analgésico em questão), concluiu-se que o esforço de lançar o produto junto a essa especialidade médica não valeria a pena.

O gerente de propaganda elaborou uma campanha promocional de lançamento e posterior sustentação, baseada no que foi decidido.

0 texto básico de todo o material promocional a ser utilizado pelos propagandistas seguia a seguinte linha mestra:

$90 \%$ das dores de cabeça são de origem vascular

\section{CEFALTON}

Terapêutica racional das dores de cabeça de origem vascular

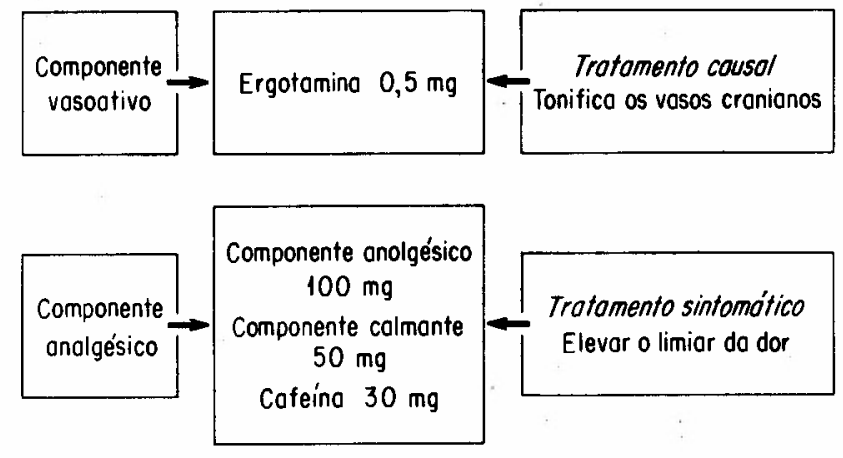

148

Vantagens complementares:

1. Rapidez de ação

2. Eficácia terapêutica

3. Tolerância excelente

Indicação: Cefaléias de origem vascular Apresentação: Vidros com 20 comprimidos

Posologia: 1 ou 2 comprimidos, ou a critério médico

\subsection{O ESTABELECIMENTO DOS OBJETIVOS}

0 gerente de marketing, tendo em vista as qualidades do novo analgésico em comparação com a dos concorrentes, e considerando, inclusive, que o preço do produto era bem mais elevado do que o preço médio dos produtos concorrentes (o que limitaria o receituário de Cefalton apenas aos consultórios particulares, quase que eliminando-o do receituário ambulatorial), calculou que seria razoável estimar uma previsão de vendas em valores para o primeiro ano, correspondente a $5 \%$ do mercado total de analgésicos éticos de uso geral, forma oral sólida.

Isso corresponderia a uma venda de $120 \mathrm{mil}$ unidades nos primeiros 12 meses, o que colocava Cefalton em sexto lugar no seu mercado e equivalia a $15 \%$ do que vendia o líder desse grupo de produtos.

\subsection{O PLANO DE MARKETING}

\section{a) Visita médica}

Cefalton foi lançado em fevereiro, com vendas de colocação nas farmácias em janeiro. 0 plano de visita médica correspondente encontra-se diagramado no anexo 3.

Além dos consultórios, o produto foi também promovido aos médicos das enfermarias de neuropsiquiatria dos hospitais e aos médicos dos ambulatórios de neuropsiquiatria do INPS.

\section{b) Anúncios}

Quatro anúncios de uma página a quatro cores foram veiculados em duas revistas médicas, uma especializada em neurologia e psiquiatria e outra de medicina geral nas edições de fevereiro e abril, e de março e maio, respectivamente.

\subsection{RESULTADOS}

Nos seus primeiros doze meses de vida, Cefalton vendeu 210 mil unidades, o que significa um superavit de $75 \%$ sobre o objetivo inicial de $120 \mathrm{mil}$ unidades.

A experiência com esse tipo de produto indica que, aquele que conquista uma posição semelhante em seu primeiro ano, poderá suportar objetivos mais ambiciosos apenas com uma campanha promocional de sustentação que o mantenha constantemente na memória dos médicos.

Considerando-se 0 aumento de vendas previsto (280 mil unidades no segundo ano) e a redução nas despesas promocionais programadas, é quase certo que Cefalton se tornará em mais um dos produtos rentáveis do laboratório já em seu segundo ano de existência, o que não é muito comum na indústria farmacêutica. 


\section{Comentários finais}

Até uns 20 anos atrás, os setores mais importantes das indústrias farmacêuticas eram as divisões internacionais de pesquisa científica, dedicadas ao descobrimento e desenvolvimento de novas substâncias químico-farmacêuticas que resultavam em novos medicamentos, e as divisões de produção. Naquela altura, as técnicas de marketing, já bem desenvolvidas na área de produtos de consumo, eram solenemente ignoradas pela indústria farmacêutica. Para os departamentos de vendas eram designados farmacêuticos, médicos ou ex-propagandistas vendedores, todos com bastante experiência no ramo, mas sem qualquer preparo teórico especifico de marketing. Talvez fossem "especialistas" em indústria farmacêutica, mas não eram "especialistas" em marketing.

Três fatores principais contribuíram para que essa situação começasse a modificar-se:

Em quase todos os países, a indústria farmacêutica vem sofrendo uma pressão legislativa rigorosa que, mesmo quando justa e benéfica para a população, cria tremendas dificuldades operacionais e reduz sua flexibilidade a limites dificeis de suportar. É o caso, por exemplo, dos controles dos preços dos produtos, das exigências para o registro de produtos, dizeres nas embalagens, patentes, tributação, etc.

0 descobrimento de medicamentos originais eficazes está-se tornando cada vez mais difícil, principalmente em função dos enormes investimentos em aparelhos e materiais necessários para o desenvolvimento da pesquisa químico-farmacêutica.

0 terceiro fator foi o próprio mercado farmacêutico que, em conseqüência dos dois primeiros fatores mencionados, vai-se tornando cada vez mais competitivo.

Assim, pouco a pouco, a indústria farmacêutica foi reconhecendo a importância das técnicas de marketing e adotando o que aprendia com a indústria de produtos de consumo popular.

Hoje, ao lado da pesquisa científica, cuja importância cresce continuamente, talvez já se possa considerar o departamento de marketing, como o principal responsável pelo sucesso ou fracasso de um laboratório farmacêutico.

A indústria farmacêutica é um dos ramos indus. triais que melhor utiliza técnicas profissionais sofisticadas e o marketing dessa mesma indústria, sem dúvida, é um novo campo que se abre para o administrador de empresas, principalmente no Brasil, onde as tendências que apontamos só começaram a ocorrer mais recentemente.

Anexo 1

Modelo de plano trimestral de visita médica

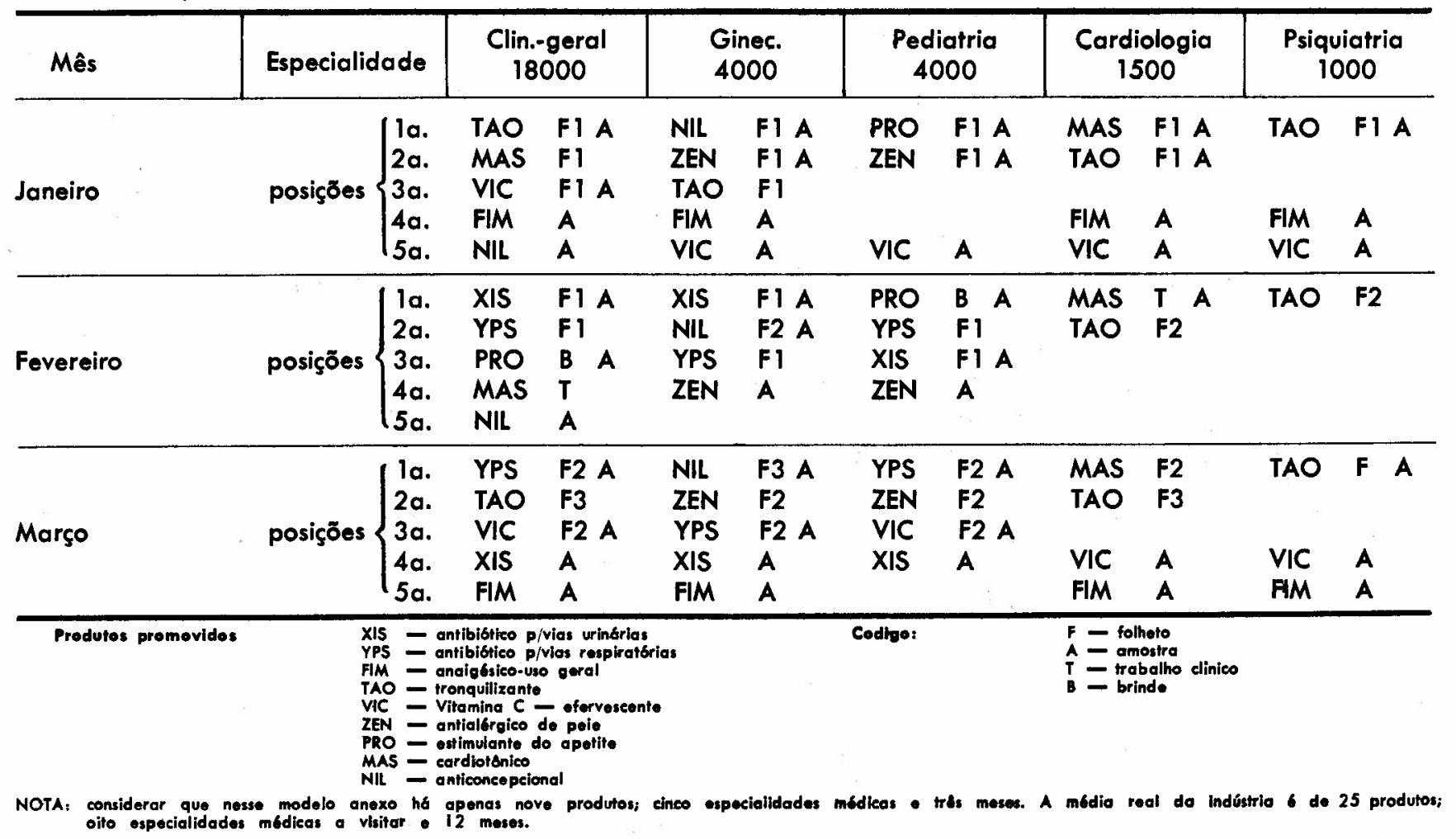


Anexo 2

Resumo do modelo do plano de visita médica

\begin{tabular}{|c|c|c|c|c|c|}
\hline & Produtos & Janeiro & Fevereiro & Março & Total \\
\hline \multirow[t]{2}{*}{$\begin{array}{l}\text { o } \\
\text { 王 } \\
\text { 온 }\end{array}$} & $\begin{array}{l}\text { FIM } \\
\text { YPS } \\
\text { NIL } \\
\text { ZEN } \\
\text { PRO } \\
\text { MAS } \\
\text { VIC } \\
\text { TAO } \\
\text { XIS }\end{array}$ & $\begin{array}{l}\bar{Z} \\
\overline{4} 000 \\
8000 \\
4000 \\
19500 \\
18000 \\
24500 \\
-\end{array}$ & $\begin{array}{c}26000 \\
4000 \\
- \\
22000 \\
1500 \\
2500 \\
26000 \\
\end{array}$ & $\begin{array}{r}26000 \\
4000 \\
8000 \\
- \\
1500 \\
22000 \\
20500 \\
-\end{array}$ & $\begin{array}{ll}52 & 000 \\
12 & 000 \\
16 & 000 \\
26 & 000 \\
22 & 500 \\
40 & 000 \\
47 & 400 \\
26 & 000 \\
\end{array}$ \\
\hline & TOTAL & 78000 & 82000 & 82000 & 242000 \\
\hline \multirow[t]{2}{*}{ 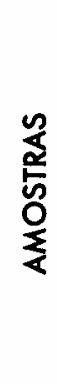 } & $\begin{array}{l}\text { FIM } \\
\text { YPS } \\
\text { NIL } \\
\text { ZEN } \\
\text { PRO } \\
\text { MAS } \\
\text { VIC } \\
\text { TAO } \\
\text { XIS }\end{array}$ & $\begin{array}{rl}24 & 500 \\
- & \\
22 & 000 \\
8 & 000 \\
4 & 000 \\
1 & 500 \\
28 & 500 \\
20 & 500\end{array}$ & $\begin{array}{c}\overline{-} \\
22000 \\
8000 \\
22000 \\
19500 \\
1000 \\
26000\end{array}$ & $\begin{array}{rl}24 & 500 \\
26 & 000 \\
4 & 000 \\
= & \\
- & 500 \\
14 & 500 \\
2 & 500 \\
26 & 000\end{array}$ & $\begin{array}{ll}49 & 000 \\
26 & 000 \\
48 & 000 \\
16 & 000 \\
26 & 000 \\
22 & 500 \\
53 & 000 \\
24 & 000 \\
52 & 000\end{array}$ \\
\hline & TOTAL & 109000 & 98500 & 109000 & 316500 \\
\hline
\end{tabular}

Anexo 3

CEFALTON - Visita médica em consultórios

\begin{tabular}{|c|c|c|c|c|c|c|c|c|c|c|c|c|c|c|c|}
\hline Médicos & Pos. & Jan. & Fev. & $M$ & ar. & & br. & Mai. & Jun. & Jul. & Ago. & Set. & Out. & Nov. & Dez: \\
\hline Clínicos-gerais & $\begin{array}{l}\text { la. } \\
2 a . \\
3 a .\end{array}$ & & F1 A2 & $\mathbf{F} 2$ & Al & $\mathbf{F 3}$ & A 1 & & & & & & & & \\
\hline Consultórios $\left(\begin{array}{ll}18 & 000\end{array}\right)$ & $\begin{array}{l}\text { 4a. } \\
5 a .\end{array}$ & & & & & & & Al & Al & Al & A1 & & & & \\
\hline Ginecol.-obstetra & $\begin{array}{l}\text { la. } \\
2 a . \\
3 a .\end{array}$ & & F1 A2 & $\mathbf{F} 2$ & Al & $\mathbf{F 3}$ & Al & & & & & & & & \\
\hline Consultórios (4 000) & $\begin{array}{l}\text { 4a. } \\
5 a .\end{array}$ & & & & & & & A 1 & A 1 & Al & A 1 & & & & \\
\hline Neuropsiquiatras & $\begin{array}{l}\text { la. } \\
2 a . \\
3 a .\end{array}$ & & F1 A2 & $\mathbf{F 2}$ & Al & $\mathbf{F 3}$ & $A_{1}$ & & & & & F2 A1 & F3 A 1 & & \\
\hline Consultórios $(1000)$ & $\begin{array}{l}4 a . \\
5 a .\end{array}$ & & & & & & & Al & $A 1$ & A 1 & Al & & & & \\
\hline
\end{tabular}

Ambulatórios de Neuropsi.

INPS (300)

$\begin{array}{lllllllllllll}\text { F1 } & \text { A1 } & \text { F2 } & \text { Al } & \text { F3 } & \text { Al } & \text { Al } & \text { A1 } & \text { Al } & \text { A1 } & \text { A1 } & \text { A1 } & \text { A1 }\end{array}$

Enfermaria de Neuropsiq. de hosp. (700)

F1 A1 F2 A1 F3 Al A1 A1 A1 A

$F 1$ - Folheto de lançamento (6 pág.)-4
$F 2$ - Folheto n.o 2 (4 pagg.)
$F 3$ - Folhoto n.0 3 (2 p6g.)

Al -1 amostro $p /$ visita

A2 - 2 amostras $p /$ visita

Revista de Administração de Empresas 